Disponível em:

http://editora.unoesc.edu.br/index.php/race

Race, Joaçaba, v. 14, n. 3, p. 925-956, set./dez. 2015

\title{
RESULTADOS DO PROGRAMA MINHA CASA MINHA VIDA SOB A PERCEPÇÃO DOS BENEFICIÁRIOS
}

\section{Results of the Program Minha Casa Minha Vida in the perception of beneficiaries}

\section{Francimar Natália Silva Cruz Reis}

E-mail: francimar.silva@ufv.com.br Mestre e Graduada em Administração pela Universidade Federal de Viçosa.

\section{Suely de Fátima Ramos Silveira}

E-mail:sramos@ufv.br

Doutora em Economia Aplicada pela Escola Superior de Agricultura Luiz de Queiroz/Universidade de São Paulo; Mestre em Economia Rural pela Universidade Federal de Viçosa; Professora do Programa de Pós-Graduação da Universidade Federal de Viçosa. Endereço para contato: Avenida Peter Henry Rolfs, s/n, Campus Universitário, 36570-000, Viçosa, Minas Gerais, Brasil.

Vinicius de Souza Moreira

E-mail:vinicius.souza@ufv.com

Graduado e mestrando em Administração pela Universidade Federal de Viçosa. 
Resumo

Neste estudo avaliaram-se os resultados do Programa Minha Casa Minha Vida (PMCMV) em âmbito municipal (Viçosa, MG), identificando a percepção dos seus beneficiários sob três dimensões: Unidade Habitacional, Empreendimento e Entorno, tendo como base a Matriz de Estrutura Lógica proposta por Reis (2013). A Análise de Cluster mostrou-se adequada para avaliar os resultados do PMCMV e promissora para estudos dessa natureza, pois permitiu eficaz identificação das variáveis que mais contribuíram para a separação dos grupos que melhor e pior avaliaram as dimensões. Com base nas análises comparativas entre as três dimensões, pode-se perceber a segregação do espaço urbano quando se trata da provisão habitacional para a população de baixa renda (interesse social). Esses indivíduos são alocados em locais distantes (regiões periféricas) das principais áreas urbanas. Considera-se, nesse sentido, que um programa que tem em seu escopo a diretriz de construir moradias que sejam capazes de promover a sustentabilidade social, ambiental e econômica dos conjuntos deve atentar-se a estudos avaliativos dessa natureza. O caso de Viçosa, MG indicou, com base na percepção daqueles que de fato usufruem do benefício, diversos pontos críticos que devem ser repensados. Assim, conhecer as percepções dos beneficiários aumenta a possibilidade de elaborar programas mais adequados à clientela, indo além da construção da moradia, ao proporcionar melhorias na qualidade de vida e no bem-estar.

Palavras-chave: Avaliação de resultados. Habitação. Matriz de Estrutura Lógica. Política pública.

\section{Results of the Program Minha Casa Minha Vida in the perception of beneficiaries}

\section{Abstract}

With this study we evaluated the results of the Program Minha Casa Minha Vida (PMCMV) at the municipal level (Viçosa, MG), identifying the perception of its beneficiaries under three dimensions: Housing Unit, Enterprise and Surrounding Areas, based on the Logical Framework proposed by Reis (2013). A Cluster Analysis was adequate to evaluate the results of PMCMV and promising for such studies because it allowed effective identification of the variables that contributed most to the separation of the groups that rated best and worst the dimensions. Based on comparative analysis of the three dimensions, one can realize the segregation of urban space when it comes to housing provision for low-income people (social interest). These individuals are allocated in remote locations (peripheral regions) of major urban areas. It is considered, that a program that has in its scope the guideline of building houses that are able to promote the social, environmental and economic sustainability of housing complexes, should pay attention to evaluative studies of this nature. The case of Viçosa, MG indicated, based on the perception of those who actually enjoy the benefit, several critical points that must be rethought. Therefore, knowing the perceptions of beneficiaries increases the possibility of developing more adequate programs to customers, going beyond the construction of housing, providing improved life quality and welfare.

Keywords: Evaluation of results. Housing. Logical Framework Approach. Public policy. 


\section{INTRODUÇÃO}

As desigualdades sociais do Brasil podem ser expressas pela ausência de adequada infraestrutura e condições habitacionais na maioria das cidades. A moradia é condição sine qua non para a existência humana digna (SOUZA, 2008). Ela representa o abrigo à família contra as intempéries e configura-se como um espaço de descanso e convívio familiar, essencial para a formação do indivíduo e do grupo ao qual pertence.

A defesa da moradia como direito social está presente na Declaração Universal dos Direitos Humanos e na Constituição da República Federativa do Brasil. A função social da moradia tem sua importância reconhecida pelo Estatuto das Cidades.

Todavia, o número de famílias que se encontram desprovidas desse direito no Brasil, ou seja, unidades habitacionais que se encontram em situação de déficit, foi estimado, no ano 2012, em 5,8 milhões de domicílios (FUNDAÇÃO JOÃO PINHEIRO, 2014). Destaca-se que essa situação afeta predominantemente as famílias com renda inferior a três salários mínimos, as quais correspondem a aproximadamente 67\% do referido déficit (FUNDAÇÃO JOÃO PINHEIRO, 2014).

A dificuldade de provimento habitacional demonstra a necessidade da ação do Estado para auxílio às famílias que se enquadram no grupo de potenciais beneficiárias de programas habitacionais de interesse social. As mudanças na Política Nacional de Habitação, no decorrer das décadas do século XX, não foram suficientes para solucionar os problemas decorrentes de tal carência e as soluções ainda constituem um desafio para os gestores públicos.

Atualmente, as iniciativas do Governo direcionadas à redução do déficit habitacional vêm estimular, além da produção de moradias de interesse social, a mobilização dos investimentos públicos para o desenvolvimento dos setores da construção civil de forma a promover a geração de trabalho e renda.

O Programa Minha Casa Minha Vida (PMCMV), lançado em abril de 2009, é, hoje, o principal programa do Governo Federal com vistas a combater o passivo habitacional brasileiro. Em 2010, findado o primeiro ano de atividades do PMCMV, foi atingida a meta de um milhão de contratações. Na segunda fase, que compreendeu o período de 2011 a 2014, tinha-se a intenção de construir 2,4 milhões de unidades habitacionais, das quais $60 \%$ deveriam estar direcionadas para famílias de baixa renda. 
Este estudo tem ênfase na parcela de habitação de interesse social, especificamente na modalidade Aquisição e Alienação de Imóveis, por meio da transferência de recursos ao Fundo de Arrendamento Residencial (FAR) no âmbito do Programa Nacional de Habitação Urbana (PNHU), cuja meta física global era a produção de 864.000 unidades habitacionais até o final de 2014. Trata-se de uma iniciativa do Governo Federal, que provê crédito imobiliário subsidiado, executado pelos municípios e em parceria com o setor privado, responsável pela construção das moradias.

Entretanto, a falta de conhecimento sobre as percepções, necessidades e valores do seu público-alvo em programas habitacionais de interesse social diminui a possibilidade de elaboração de programas mais adequados à sua clientela, o que vem a comprometer o seu desempenho. Os beneficiários raramente participam diretamente do processo de desenvolvimento do produto e, por essa razão, suas necessidades não são normalmente capturadas e convertidas em requisitos, os quais, em consequência, não são adequadamente considerados pela equipe de projeto (LIMA; FORMOSO; ESCHEVESTE, 2011), e, assim, passa a prevalecer o interesse de mercado.

O monitoramento e a avaliação (M\&A) constituem fases do ciclo de políticas públicas e são essenciais para o aperfeiçoamento das iniciativas governamentais, devendo estar presentes em todas as etapas da política e dos seus programas (ROSSI; LIPSEY; FREEMAN, 2004; WOLLMANN; HELLMUT, 2007; MORRA-IMAS; RIST, 2009). Sob a perspectiva do M\&A, as pesquisas de satisfação e/ou percepção dos moradores sobre o ambiente construído são fundamentais em uma avaliação de pós-ocupação. Elas têm fornecido informações importantes sobre os pontos positivos e negativos de um projeto, sob a ótica do seu principal experimentador, o morador (MORAES; ABIKO, 2006). Ornstein e Roméro (1992), por sua vez, indicam que o estabelecimento de rotinas de avaliação dos programas sociais que considerem o desempenho físico e os níveis de satisfação dos beneficiários no decorrer da utilização permite diminuir o número de erros das intervenções, em muitos casos, possíveis de serem evitados.

Portanto, diante do contexto ora exposto, a questão que se coloca como problemática de investigação é: quais são os resultados do PMCMV em Viçosa, MG sob a percepção de seus beneficiários?

Para responder ao questionamento supracitado, propôs-se, neste estudo, a avaliar os resultados do Programa Minha Casa Minha Vida em âmbito municipal (Viçosa, MG) com ênfase na percepção dos seus beneficiários, sob três dimensões: 
unidade habitacional, empreendimento e entorno. Ressalta-se que as dimensões estabelecidas são derivadas da Matriz de Estrutura Lógica (MEL) desenvolvida por Reis (2013). Além disso, a avaliação se baseou nos aspectos técnicos dos produtos entregues pela intervenção, não eximindo das análises as considerações sobre tais resultados no cotidiano das famílias entrevistadas.

Espera-se, nesse sentido, contribuir para os estudos direcionados ao M\&A, tanto em termos teóricos quanto metodológicos, uma vez que são adotadas as percepções daqueles que de fato usufruem dos principais produtos entregues pelo programa habitacional em tela, sendo utilizados, para tanto, procedimentos estatísticos multivariados.

\section{REFERENCIAL TEÓRICO}

\subsection{MONITORAMENTO E AVALIAÇÃO NO CONTEXTO HABITACIONAL}

A avaliação de programas sociais, especificamente os de habitação de interesse social, adquirem importância para a gestão, pois fornecem a possibilidade de aperfeiçoamento da política com vistas à melhor alocação dos recursos e ao aumento do bem-estar da população.

Dessa forma, o processo de avaliação se faz necessário frente às ações governamentais. Cohen e Franco (2008, p. 77) definem avaliação como “[...] uma atividade que tem como objetivo maximizar a eficácia dos programas na obtenção de seus fins e a eficiência na alocação de recursos para a consecução dos mesmos."

De forma complementar, a avaliação compreende o processo de medição sistemática da operação e/ou dos resultados de um projeto, programa ou política, em relação ao desempenho, eficácia e impacto (ambos esperados ou não) considerando os objetivos predeterminados (implícitos ou explícitos), como forma de contribuir para o aprimoramento das ações que são realizadas (MORRA-IMAS; RIST, 2009; ROSSI; LIPSEY; FREEMAN, 2004).

Avaliar a gestão é importante para corrigir rumos indesejados que podem estar sendo tomados desapercebidamente. Avaliações periódicas permitem identificar e aproveitar oportunidades de ação para solucionar problemas, reduzir desperdícios ou realizar ações para atingir compromissos de governo (CALDAS; KAYANO, 2001). 
O monitoramento é a “avaliação” contínua da implementação do projeto. Ele fornece aos gestores e a outras partes interessadas umfeedback e identifica sucessos reais ou potenciais e problemas, de modo a facilitar os ajustes oportunos para a operação do projeto (WORLD BANK, 1996). Ressalta-se que monitoramento e avaliação estão inter-relacionados, mas não são sinônimos (ORTEGON; PACHECO; PRIETO, 2005). No entanto, os objetivos de monitoramento e de avaliação são muito semelhantes: fornecer informações que podem ajudar a informar as decisões, melhorar o desempenho e atingir os resultados planejados (UNITED NATIONS DEVELOPMENT PROGRAME, 2002).

Assim, enquanto o acompanhamento ou o monitoramento é a atividade gerencial interna que se realiza durante o período de execução e operação, a avaliação pode ser realizada tanto antes ou durante a implementação quanto ao concluí-la ou mesmo algum tempo depois, para quando se prevê que o projeto provocou todo o seu impacto (COHEN; FRANCO, 2008).

Os indicadores de resultado mensuram os efeitos do Programa com a população-alvo e os usuários do Programa. No primeiro caso, devem ser levantados dois tipos de indicadores de resultado, com pesquisas de campo ou com o auxílio de bases de dados e/ou cadastros já existentes. Na avaliação de resultados com os usuários do Programa, podem ser utilizados indicadores de aferição de benefícios, que consideram os objetivos específicos de cada programa ou projeto (COSTA; CASTANHAR, 2003).

Vos (1996) traz exemplos de indicadores comumente utilizados quando o estudo enfoca os usuários do Programa e a população-alvo, quais sejam: déficit quantitativo de moradias, qualidade de construção da moradia e disponibilidade de serviços básicos.

A avaliação de empreendimentos habitacionais tem importância no esforço de melhoria da habitação de interesse social, podendo auxiliar na avaliação de resultados e na identificação de erros e acertos diante dos objetivos do projeto. Com frequência, as avaliações realizadas nos empreendimentos de habitação de interesse social têm como foco os atributos do produto, estabelecendo pouca conexão com os fins esperados (BONATTO; MIRON; FORMOSO, 2011).

Woodruff e Gardial (1996) chamam atenção para o fato de que, no desenvolvimento das avaliações, geralmente os clientes são interrogados apenas no que diz respeito aos principais atributos relacionados ao produto entregue. Segundo os referidos autores, de forma a possibilitar maior entendimento sobre a geração de valor para esses usuários, é necessário que as consequências do produto em uso e os 
objetivos esperados também sejam explorados, explicitando os diferentes níveis de abstração na percepção dos resultados.

Assim, e também considerando os recursos investidos em programas habitacionais, atenta-se para a importância da formação da satisfação e da geração de valor para a população atendida, a fim de que realmente esses benefícios ocorram de forma duradoura, resultando em melhoria do seu bem-estar (BONATTO; MIRON; FORMOSO, 2011). A satisfação do morador se trata de um conceito que procura apreender a avaliação do indivíduo sobre as suas condições de moradia e serviços urbanos, bem como os efeitos provenientes da execução do projeto na vida social e comunitária (BRASIL, 2009).

\subsection{MARCO LÓGICO E MATRIZ DE ESTRUTURA LÓGICA}

O Marco Lógico facilita a sumarização dos elementos centrais do projeto e explicita a lógica existente por trás dele. De acordo com Bamberger, Rugh e Mabry (2006), o Marco Lógico é a teoria (ou modelo) que mostra como se espera que o Programa leve aos resultados observados ou desejados. Basicamente, um modelo lógico é a forma sistemática e visual para apresentar e partilhar a sua compreensão das relações entre os recursos que o gestor tem para operar o seu programa, as atividades que planeja e as mudanças ou resultados que espera alcançar (W.K. KELLOGG FOUNDATION, 2004).

De forma mais ampla, o Banco Interamericano de Desarrollo (1997) define o Marco Lógico como uma ferramenta para facilitar o processo de conceitualização, elaboração, execução e avaliação de projetos. Pode ser utilizado em todas as etapas de preparação do projeto: programação, identificação, orientação, análise, apresentação perante os comitês de revisão, execução e avaliação.

O Marco Lógico, por sua vez, é estruturado em uma matriz quatro por quatro: as colunas (fornecem o resumo narrativo dos objetivos e das atividades); os indicadores (resultados específicos a alcançar); os meios de verificação; e as hipóteses ou supostos (fatores externos que implicam riscos) (BANCO INTERAMERICANO DE DESARROLLO, 1997). As quatro linhas apresentam informação acerca dos objetivos, indicadores, meios de verificação e hipóteses em quatro momentos diferentes da vida do projeto (ORTEGON; PACHECO; PRIETO, 2005), sendo eles: Atividades, Produtos, Resultados e Impactos, conforme ilustrado no Diagrama 1. 


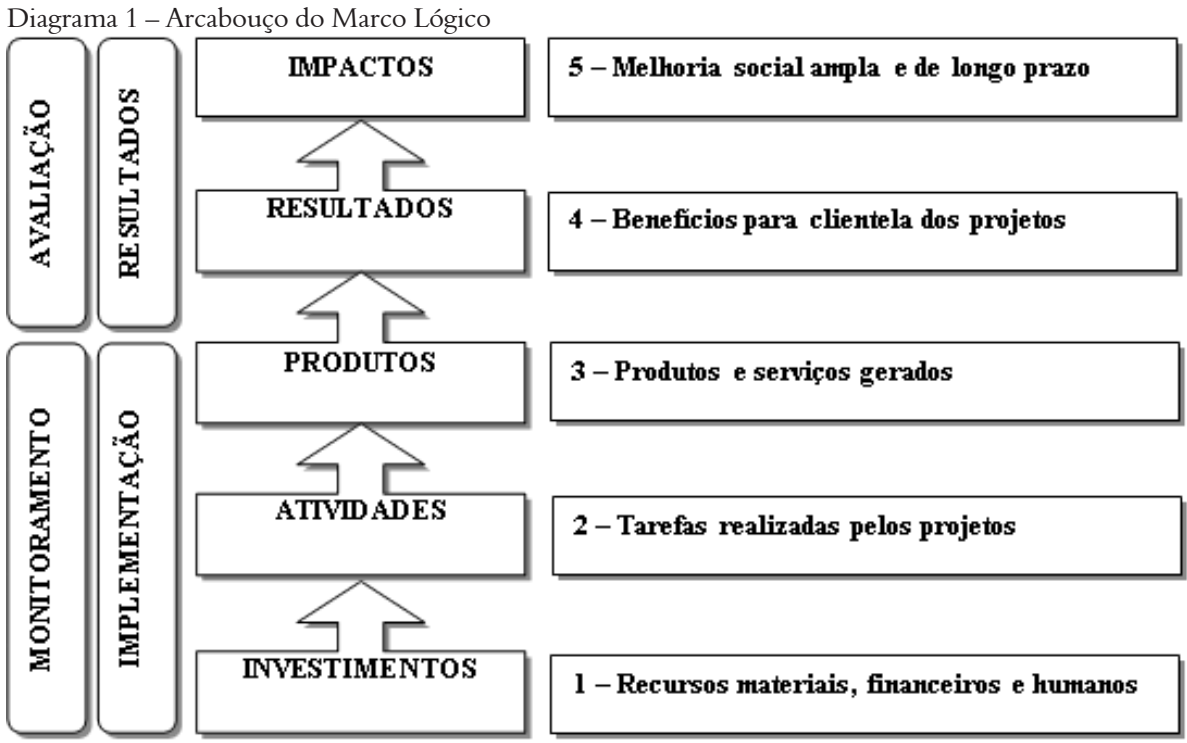

Fonte: adaptado de Banco Mundial (2004).

Nota-se que o Monitoramento tem como objetivos os níveis de Atividades e Produtos. A Avaliação concentra-se nos níveis de Resultados e Impactos. Entretanto, os Resultados e os Impactos, com frequência, ficam de fora do Monitoramento e da Avaliação.

A tendência é a concentração dos estudos nos níveis de atividades e produtos, itens nos quais os dados são mais facilmente disponíveis. Esses dois níveis dizem menos a respeito do efetivo grau de sucesso do projeto ou programa, que é basicamente medido pelos Resultados. Portanto, a recomendação é que a prioridade do Monitoramento e da Avaliação no Marco Lógico seja na Avaliação dos Resultados. A proposta do nível de Resultados é incorporar a variável percepção do beneficiário, cliente e alvo da política, bem como sua experiência no uso dos produtos (VILLAROSA; ABIKO, 2015).

\section{O PROGRAMA MINHA CASA MINHA VIDA}

Lançado em abril de 2009, durante o segundo mandato de Luís Inácio Lula da Silva (2007-2010), o PMCMV tem por finalidade a criação de mecanismos que incentivem à produção e aquisição de novas unidades habitacionais ou requalificação de imóveis urbanos e à produção ou reforma de habitações rurais e compreende os 
seguintes subprogramas: o Programa Nacional de Habitação Urbana (PNHU) e o Programa Nacional de Habitação Rural (PNHR).

De modo a contextualizar as linhas de atuação do Programa, situando a linha-alvo específica do estudo (PMCMV/FAR), traz-se o Diagrama 2.

Diagrama 2 - PMCMV: Programas e linhas de atuação

Programa Minha Casa, Minha Vida

Programa Nacional de Habitação Urbana

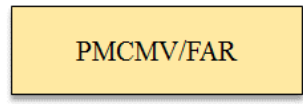

\section{PMCMV/Entidades}

Programa Nacional de Habitação Rural

PMCMV/Rural
PMCMV/Oferta

Pública de Recursos

Fonte: os autores.

A aquisição e a alienação de imóveis por meio da transferência de recursos ao Fundo de Arrendamento Residencial (FAR), no âmbito do PNHU e integrante do PMCMV, trata-se de uma das modalidades do Programa destinada à Habitação de Interesse Social (HIS) e tem por objetivo, conforme a Portaria n. 465, de 03 de outubro de 2011, a aquisição e requalificação de imóveis destinados à alienação para famílias com renda mensal de até $1.600,00$ por meio de operações realizadas por instituições financeiras oficiais federais.

As principais diretrizes do PMCMV/FAR visam promover a melhoria da qualidade de vida das famílias beneficiadas; prover habitações que garantam a sustentabilidade social, econômica e ambiental aos projetos e integrá-los a outras intervenções ou programas governamentais; criar novos postos de trabalho, especialmente por meio da cadeia produtiva da construção civil; executar o Trabalho Social; reservar, no mínimo, $3 \%$ das unidades habitacionais para o atendimento aos idosos; entre outras.

Diversos são os atores sociais envolvidos nessa modalidade, sendo eles: o Ministério das cidades, a Caixa Econômica Federal, instituições financeiras oficiais federais, o Distrito Federal, estados e municípios ou respectivos órgãos das administrações direta ou indireta, e empresas do setor da construção civil. 
No âmbito do Programa, admite-se a contratação de empreendimentos na forma de condomínio, constituído de apartamentos ou loteamento, composto por casas térreas. Os valores máximos de aquisição das unidades, observadas as áreas de atuação definidas (capital e respectiva região metropolitana, municípios entre 20 e 50 mil habitantes e demais municípios) variam conforme a Unidade Federativa.

As principais diretrizes para a elaboração dos projetos de intervenção preconizam que os empreendimentos observem as especificações técnicas mínimas disponíveis para a consulta nos normativos do Programa. Outra indicação é que estejam inseridos na malha urbana ou em zonas de expansão urbana, assim definidas pelo Plano Diretor. Aqueles localizados em zona de expansão urbana deverão estar contíguos à malha urbana e possuir no entorno áreas destinadas para atividades comerciais locais.

Ressalta-se, ainda, que os empreendimentos sejam dotados de infraestrutura urbana básica: vias de acesso e de circulação pavimentadas, drenagem pluvial, calçadas, guias e sarjetas, rede de energia elétrica e iluminação pública, rede para abastecimento de água potável, soluçõos para o esgotamento sanitário e coleta de lixo.

As redes de energia elétrica e iluminação pública, o abastecimento de água potável e as soluções para o esgotamento sanitário deverão estar operantes até a data de entrega do empreendimento ou da respectiva etapa.

A seleção do beneficiário é realizada pelo Ente Federativo competente (estado, município ou Distrito Federal) e analisada pela instituição financeira se as condições se enquadram nas exigências do Programa. Além disso, o beneficiário não pode ter sido beneficiado anteriormente em programas de habitação social do Governo e não pode possuir casa própria ou financiamento em qualquer Unidade da Federação.

\section{PERCURSO METODOLÓGICO}

\subsection{CARACTERÍSTICAS DO ESTUDO}

A presente pesquisa trata-se de um estudo descritivo, pois permitiu descrever e expor as características dos beneficiários quanto à sua percepção sobre o Conjunto Habitacional Benjamim José Cardoso, o primeiro contratado e entregue no âmbito do PMCMV/FAR, no Município de Viçosa, região da Zona Mata do Estado de 
Minas Gerais. O empreendimento é composto por 132 unidades habitacionais e está alocado na região periférica do Município.

Justifica-se a escolha do Município em questão, para a realização deste estudo, em razão da facilidade em acompanhar de perto a implementação do Programa e pelo acesso facilitado às famílias beneficiadas e aos demais agentes envolvidos (Prefeitura Municipal de Viçosa, Secretaria de Ação Social do Município e agentes da Caixa Econômica Federal).

Ademais, Viçosa apresenta comportamento demográfico similar às demais cidades do Brasil e de Minas Gerais, isto é, a partir da década de 1970, recebeu grandes levas de migrantes, o que representou o crescimento acelerado da população urbana. Tal crescimento convergiu para a formação de espaços urbanos nos quais a pobreza é predominante, em decorrência, principalmente, dos problemas relacionados ao acesso ao trabalho, à habitação e à infraestrutura (SANTOS, 1991).

\subsection{COLETA DE DADOS}

O processo de Avaliação de Resultados teve como base a Matriz de Estrutura Lógica (MEL) do PMCMV proposta por Reis (2013). A opção feita pelo Marco Lógico decorreu de sua simplicidade em apresentar um conjunto de conceitos interdependentes que descrevem de modo operacional e organizado, em uma matriz, os aspectos mais importantes do projeto de intervenção. Isso permite o acompanhamento sistemático e a avaliação mais fácil e objetiva (PFEIFFER, 2000).

A Matriz de Estrutura Lógica foi utilizada para estruturar a construção do questionário. Assim, definiram-se três constructos: unidade habitacional, empreendimento e entorno, com base na MEL do PMCMV. No Quadro 1 está a descrição de cada dimensão.

A geração dos dados primários foi por meio de entrevista pessoal com aplicação de questionário estruturado. $O$ instrumento de coleta de dados foi subdivido de acordo com as três dimensões; as questões, associadas a uma escala de pontos, tinham como respostas possíveis: 1 = "Péssimo", 2 = "Ruim", $3=$ "Regular", 4 = "Bom" e 5 = "Ótimo". Além disso, atribuiu-se 99 = "Não soube ou não respondeu" aos itens não respondidos, tendo sidos considerados dados perdidos nas análises. 
Quadro 1 - Dimensões e suas definições

\begin{tabular}{|l|l|}
\hline \multicolumn{1}{|c|}{ Dimensão } & \multicolumn{1}{c|}{ Descrição } \\
\hline $\begin{array}{l}\text { Unidade } \\
\text { habitacional }\end{array}$ & $\begin{array}{l}\text { Representa a moradia que dispõe de padrão de adequação ao uso, qualidade } \\
\text { da construção (solidez e durabilidade), segurança, conforto ambiental, apa- } \\
\text { rência e privacidade, além de atender às especificações mínimas estabelecidas } \\
\text { pelo Programa. }\end{array}$ \\
\hline Empreendimento & $\begin{array}{l}\text { Representa as edificações e o agrupamento de edificações de empreendimen- } \\
\text { tos de interesse social (o conjunto habitacional). Deve-se situar em terrenos } \\
\text { que disponham (ou que sejam capazes de viabilização) de infraestrutura } \\
\text { básica (rede pública de abastecimento de água; iluminação pública; esgota- } \\
\text { mento sanitário; drenagem pluvial, coleta de lixo, ruas e calçadas pavimenta- } \\
\text { das); possibilidade de atendimento por transporte público e proximidade de } \\
\text { equipamentos públicos, capazes de atender à demanda prevista. Deve atender, } \\
\text { também, conforme a tipologia do empreendimento, às especificidades dos } \\
\text { normativos do Programa. }\end{array}$ \\
\hline Entorno & $\begin{array}{l}\text { Representa as redondezas e os bairros próximos e vizinhos ao empreendi- } \\
\text { mento, bem como a sua infraestrutura e equipamentos públicos (e seus res- } \\
\text { pectivos serviços), capazes de atender à demanda prevista. }\end{array}$ \\
\hline
\end{tabular}

Fonte: adaptado de Reis (2013).

Também foi realizada uma entrevista semiestruturada com um dos primeiros representantes de bairro. De acordo com Triviños (1987), essa tipologia de entrevista tem como característica questionamentos básicos que são ancorados em teorias e hipóteses que se relacionam ao tema da pesquisa e favorece não apenas a descrição dos fenômenos sociais, mas também sua explicação e a compreensão de sua totalidade.

Na pesquisa de campo foram aferidas as respostas de 100 famílias. Das 32 moradias restantes, constatou-se que havia oito casas em situação irregular, sendo três desocupadas (duas delas depredadas) e cinco em que os moradores não eram os beneficiários diretos (repasse para parentes/conhecidos e invasões). Cinco famílias se recusaram a responder ao questionário e 19 não foram encontradas durante os dias selecionados para o estudo.

\subsection{TRATAMENTO E ANÁLISE DOS DADOS}

Para verificar a confiabilidade dos constructos, utilizou-se a técnica do Alfa de Cronbach. Conforme Martins (2007), o constructo é uma variável, ou conjunto de variáveis, ou seja, uma definição operacional que busca representar o verdadeiro 
significado teórico de um conceito. O coeficiente Alfa de Cronbach varia de 0 a 1 . Os pesquisadores normalmente consideram, para pesquisas sociais, um corte de 0,6.

Utilizou-se, também, a Análise de Cluster para agrupar as famílias em dois grupos - as que melhor e as que pior avaliaram cada uma das dimensões - para distinguí-las entre as que apresentaram as melhores ou piores percepções sobre os resultados do Programa.

A Análise de Conglomerados, ou Análise Cluster, é uma técnica de interdependência que busca agrupar os elementos conforme sua estrutura "natural" (FÁVERO et al., 2009). Considera-se um grupo ou Cluster homogêneo se seus membros estão próximos uns dos outros; mas membros desse grupo diferem-se consideravelmente daqueles de outro grupo (MARDIA; KENT; BIBBY, 1979). Os agrupamentos devem exibir elevada homogeneidade interna (dentro do agrupamento) e elevada heterogeneidade externa (entre agrupamentos) (HAIR JUNIOR et al., 1998).

$\mathrm{Na}$ Análise de Cluster, obtêm-se os agrupamentos usando técnicas hierárquicas ou não hierárquicas. A probabilidade de classificação errada de determinado sujeito em determinado Cluster é menor nos métodos não hierárquicos (MAROCO, 2007). Os procedimentos não hierárquicos são utilizados quando o número inicial de Clusters é definido pelo pesquisador (FÁVERO et al., 2009). Portanto, pelo aspecto de predefinição do número de Clusters, utilizou-se o algoritmo de agrupamento não hierárquico com a medida de distância k-means.

Uma vez que os sujeitos são agrupados no Cluster de modo que dentro do agrupamento sejam tão próximos quanto possível e fora do Cluster sejam tão dessemelhantes quanto possível, as diferenças entre as médias dos Clusters hão de ser significativamente diferentes em pelo menos uma das variáveis. Portanto, a utilidade da Anova não é verificar se os Clusters são ou não diferentes, mas identificar qual ou quais das variáveis permitem a separação deles (MAROCO, 2007).

Por meio da Anova, pode-se afirmar que, se uma variável conseguir distinguir bem os agrupamentos, é de se esperar que sua variabilidade entre grupos seja elevada. Portanto, as variáveis que mais discriminam os grupos são aquelas com maior valor da estatística F (FÁVERO et al., 2009).

Se uma variável discriminar bastante entre os Clusters, então a variabilidade desta entre os Clusters há de ser elevada. Pelo contrário, dentro do Cluster há de ser pequena. As variáveis que mais contribuem para a formação dos Clusters são aquelas com maior Cluster Mean Square (QMC - quadrado médio do Cluster) e menor Error 
Mean Square (QME - quadrado médio do erro), ou seja, aquelas com maior valor da estatística F (F=QMC/QME) (MAROCO, 2007).

Ressalta-se que as análises dos dados foram realizadas por meio de procedimentos estatísticos dos programas Statistical Package for the Social Sciences

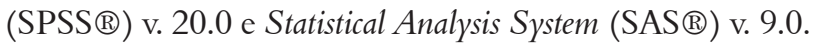

As observações registradas in loco, uma vez que as entrevistas foram realizadas nas próprias residências dos beneficiários, foram utilizadas para a construção do estudo. A vivência dos pesquisadores e as conversas com beneficiários, ao longo da pesquisa de campo, trouxeram importantes informações complementares à análise estatística dos dados.

\section{RESULTADOS E DISCUSSÕES}

\subsection{VALIDAÇÃO DOS CONSTRUCTOS}

O processo de validação do instrumento de coleta de dados, derivado da Matriz de Estrutura Lógica (REIS, 2013) do PMCMV, com ênfase na percepção dos seus beneficiários, foi realizado por meio do teste de confiabilidade Alfa de Cronbach. Obteve-se, nesse sentido, coeficiente de 0,825 para a dimensão unidade habitacional; de 0,735 para o empreendimento; e de 0,921 para o entorno. Logo, todas as dimensões foram superiores ao corte sugerido de 0,6 para pesquisas dessa natureza e traduzem com confiabilidade os conceitos que representam.

\subsection{A PERCEPÇÃO DAS FAMÍLIAS BENEFICIADAS}

Utilizou-se a Análise de Cluster para agrupar as famílias em cada uma das dimensões do PMCMV (Unidade Habitacional, empreendimento e entorno), sob dois grupos: Cluster 1 - "Melhor avaliação da percepção" e Cluster 2 - "Pior avaliação da percepção”. A seguir, apresentam-se os Clusters e a Análise de Variância (Anova) e suas caracterizações. 


\subsubsection{Unidade Habitacional}

$\mathrm{Na}$ Tabela 1 apresenta-se a caracterização dos dois clusters formados a partir da dimensão Unidade Habitacional (UH). Observa-se que o Cluster 1 - "Melhor Avaliação" apresenta, conforme esperado, médias maiores em todas as variáveis quando comparado ao Cluster 2 - "Pior Avaliação". A média geral das variáveis do primeiro Cluster foi de 3,74, enquanto o segundo obteve 3,05.

Tabela 1 - Caracterização dos Clusters da Dimensão Unidade Habitacional (continua)

\begin{tabular}{llcc}
\multicolumn{1}{c}{ Cluster } & \multicolumn{1}{c}{ Variável } & Média & $\begin{array}{c}\text { Desv. } \\
\text { padrão }\end{array}$ \\
\hline & Tamanho da UH & 4,02 & 0,66 \\
& Tamanho da cozinha & 2,89 & 0,84 \\
& Tamanho do banheiro & 3,98 & 0,59 \\
& Tamanho da sala de estar & 4,14 & 0,55 \\
& Tamanho do dormitório casal & 4,18 & 0,58 \\
& Tamanho dod duas pessoas & 4,04 & 0,68 \\
& Tamanho da área de serviço & 3,75 & 0,81 \\
& Disposição dos cômodos & 3,95 & 0,64 \\
$\mathbf{1}$ & Adaptação aos integrantes & 4,23 & 0,71 \\
Nelhor Avaliação & Materiais de revestimento & 3,48 & 0,87 \\
& Portas e janelas & 3,20 & 0,95 \\
& Instalações hidráulicas & 3,82 & 0,69 \\
& Instalações elétricas & 3,91 & 0,52 \\
& Telhado & 3,20 & 1,02 \\
Segurança & 3,00 & 1,18 \\
& Iluminação natural & 4,23 & 0,48 \\
Ventilação & 3,93 & 0,73 \\
Barulhos e ruídos & 3,27 & 1,06 \\
Temperatura no inverno & 3,61 & 0,78 \\
Temperatura no verão & 3,18 & 1,08 \\
Aparência & 4,25 & 0,61 \\
\hline
\end{tabular}


(conclusão)

\begin{tabular}{|c|c|c|c|}
\hline Cluster & Variável & Média & $\begin{array}{c}\text { Desv. } \\
\text { padrão }\end{array}$ \\
\hline \multirow{22}{*}{$\begin{array}{l}2 \\
\mathrm{Na}=56 \\
\text { Pior Avaliação }\end{array}$} & Tamanho da UH & 3,32 & 0,88 \\
\hline & Tamanho da cozinha & 1,61 & 0,71 \\
\hline & Tamanho do banheiro & 3,45 & 0,97 \\
\hline & Tamanho da sala de estar & 3,69 & 0,63 \\
\hline & Tamanho do dormitório casal & 3,68 & 0,66 \\
\hline & Tamanho do dormitório duas pessoas & 3,57 & 0,66 \\
\hline & Tamanho da área de serviço & 2,65 & 1,14 \\
\hline & Disposição dos cômodos & 3,50 & 0,79 \\
\hline & Adaptação aos integrantes & 3,47 & 0,90 \\
\hline & Materiais de revestimento & 2,39 & 1,14 \\
\hline & Portas e janelas & 2,18 & 1,04 \\
\hline & Instalações hidráulicas & 3,02 & 1,07 \\
\hline & Instalações elétricas & 3,57 & 0,90 \\
\hline & Telhado & 2,38 & 1,22 \\
\hline & Segurança & 1,46 & 0,76 \\
\hline & Iluminação natural & 3,93 & 0,85 \\
\hline & Ventilação & 3,32 & 1,22 \\
\hline & Barulhos e ruídos & 2,93 & 1,26 \\
\hline & Temperatura no inverno & 3,18 & 0,94 \\
\hline & Temperatura no verão & 2,44 & 1,03 \\
\hline & Aparência & 3,91 & 0,92 \\
\hline & Privacidade entre os moradores da UH & 3,51 & 1,12 \\
\hline
\end{tabular}

Fonte: os autores.

Nota: ${ }^{a}$ Número de famílias em cada cluster.

A Análise de Variância para as variáveis da dimensão unidade habitacional é apresentada na Tabela 2, e sua interpretação permite identificar quais contribuíram para a separação dos Clusters. 
Tabela 2 - Anova da dimensão Unidade Habitacional

\begin{tabular}{|c|c|c|c|c|c|c|}
\hline \multirow[b]{2}{*}{ Variável } & \multicolumn{2}{|c|}{ Cluster } & \multicolumn{2}{|c|}{ Error } & \multirow[b]{2}{*}{$\mathbf{F}$} & \multirow[b]{2}{*}{ Sig. } \\
\hline & $\begin{array}{c}\text { Mean } \\
\text { Square }\end{array}$ & df & $\begin{array}{c}\text { Mean } \\
\text { Square }\end{array}$ & df & & \\
\hline Tamanho da U H & 12,118 & 1 & 0,624 & 98 & 19,408 & 0,000 * \\
\hline Tamanho da cozinha & 40,321 & 1 & 0,590 & 98 & 68,377 & 0,000 * \\
\hline Tamanho do banheiro & 6,943 & 1 & 0,682 & 98 & 10,184 & 0,002 * \\
\hline Tamanho da sala de estar & 4,851 & 1 & 0,360 & 97 & 13,471 & 0,000 * \\
\hline Tamanho do dormitório casal & 6,240 & 1 & 0,396 & 98 & 15,778 & 0,000 * \\
\hline Tamanho do dormitório duas pessoas & 5,537 & 1 & 0,445 & 98 & 12,438 & 0,001 夫 \\
\hline Tamanho da área de serviço & 29,334 & 1 & 1,017 & 97 & 28,833 & 0,000 * \\
\hline Disposição dos cômodos & 5,091 & 1 & 0,530 & 98 & 9,611 & 0,003 * \\
\hline Adaptação aos integrantes & 13,917 & 1 & 0,675 & 97 & 20,63 & 0,000 * \\
\hline Qualidade portas e janelas & 25,568 & 1 & 1,004 & 97 & 25,479 & 0,000 * \\
\hline Qualidade instalações hidráulicas & 15,504 & 1 & 0,849 & 96 & 18,256 & 0,000 * \\
\hline Qualidade instalações elétricas & 2,721 & 1 & 0,571 & 96 & 4,764 & 0,032 * \\
\hline Qualidade do telhado & 16,546 & 1 & 1,300 & 97 & 12,724 & 0,001 * \\
\hline Segurança & 58,111 & 1 & 0,938 & 98 & 61,949 & 0,000 * \\
\hline Iluminação natural & 2,248 & 1 & 0,509 & 97 & 4,414 & 0,038 * \\
\hline Ventilação & 9,180 & 1 & 1,072 & 98 & 8,567 & 0,004 * \\
\hline Barulhos e ruídos & 2,917 & 1 & 1,386 & 97 & 2,105 & $0,150 \star \star$ \\
\hline Temperatura no inverno & 4,558 & 1 & 0,769 & 97 & 5,926 & 0,017 * \\
\hline Temperatura no verão & 13,584 & 1 & 1,114 & 97 & 12,192 & 0,001 * \\
\hline Aparência & 2,836 & 1 & 0,641 & 98 & 4,426 & 0,038 * \\
\hline Privacidade entre os moradores & 8,229 & 1 & 0,868 & 96 & 9,475 & 0,003 * \\
\hline Qualidade materiais de revestimento & 28,976 & 1 & 1,065 & 98 & 27,216 & 0,000 * \\
\hline
\end{tabular}

Fonte: os autores.

Nota: *significativo a $5 \%, \star \star$ não significativo.

Conforme exposto na Tabela 2, observa-se que com exceção da variável barulhos e ruídos, as demais utilizadas no constructo foram significativas para a formação dos Clusters, ao nível de significância de 5\%.

Com base nos valores da estatística $\mathrm{F}$, identificou-se que as variáveis tamanho da cozinha $(\mathrm{F}=68,377)$; segurança da $U H$ contra assaltos, roubos e invasões $(\mathrm{F}=61,949)$; tamanho da área de serviço $(\mathrm{F}=28,833)$; e qualidade dos materiais de revestimento de pisos e paredes $(\mathrm{F}=27,216)$; qualidade das portas e janelas $(\mathrm{F}=25,479)$ foram as mais importantes para discriminar as famílias que melhor avaliaram a Unidade Habitacional das famílias que pior avaliaram. 
Nota-se que as referidas variáveis possuem maior variabilidade externa (quando comparadas às demais), isto é, entre os Clusters, o que pode ser observado na coluna Cluster Mean Square. Dada essa magnitude, ainda que a variabilidade interna dessas variáveis não seja a menor (conforme disposto na coluna ErrorMean Square), o teste F foi significativo, como supramencionado.

Destaca-se a importância da variável tamanho da cozinha ao refletir quantitativamente as opiniões dos entrevistados que argumentavam sobre a falta de espaço nesse cômodo para distribuírem os móveis (principalmente a mesa), utensílios e eletrodomésticos a ela necessários. Os beneficiários também registraram insatisfação com a incapacidade do cômodo em comportar toda a família no momento das principais refeições.

A área de serviço também é outra variável que deve ser observada na fase de elaboração dos projetos. Segundo relatos dos beneficiários, esse cômodo é externo e apresenta pequena cobertura, com espaço insuficiente para alocar os utensílios e realizar as atividades necessárias.

A relevância da variável segurança na Análise de Cluster condiz com o relato dos entrevistados em não se sentirem seguros nas suas casas, pois houve casos de assaltos, roubos e invasões. Acrescenta-se a esse cenário a significância das percepções sobre a variável qualidade das portas e janelas, que reflete a baixa resistência e qualidade do material e fácil transposição dos limites da residência. Os relatos dos moradores apontaram que as chaves de algumas casas abriam as fechaduras de outras e as janelas eram facilmente destravadas pelo lado de fora da moradia.

A problemática observada nas variáveis segurança e qualidade das portas e janelas implicou a realização, por parte das famílias, de diversas melhorias na habitação, como muros ou cercas ao redor de suas casas, além da instalação de grades em portas e/ou janelas.

Por fim, comenta-se sobre a qualidade dos materiais de revestimento de pisos e paredes, significativa na análise, pois na época em que o Programa foi contratado, o normativo vigente estabelecia a obrigatoriedade de pisos e azulejos em cerâmica apenas para áreas molhadas (cozinha e banheiro). Logo, isso resultou em quartos, sala e área de serviço sem revestimentos cerâmicos, e constatou-se que $61 \%$ das famílias promoveram em suas casas melhorias nos pisos e paredes.

Confirmando os resultados apresentados, verificou-se que $82 \%$ das famílias realizaram alterações (reformas, ampliações e melhorias) na Unidade Habitacional, sendo 98\% destas relativas às variáveis supracitadas, com maior significância nos valores da estatística F. 
Em Viçosa, MG, a grande maioria das famílias beneficiadas do PMCMV avaliou a Unidade Habitacional com menos índices na escala. Esse fato fornece importante sinalização para os gestores do Programa no Município, bem como para os demais envolvidos na implementação do Programa.

\subsubsection{Empreendimento}

Na Tabela 3 apresenta-se a caracterização dos dois Clusters formados a partir da dimensão empreendimento. Observa-se que o Cluster - "Melhor Avaliação" apresenta médias superiores na quase totalidade das variáveis às observadas no Cluster 2, denominado "Pior Avaliação". A média geral, por sua vez, acentua ainda mais a diferença entre os agrupamentos: o primeiro Cluster obteve escore de 3,47, enquanto o segundo, de 2,88 pontos.

Tabela 3 - Caracterização dos Clusters da dimensão Empreendimento

\begin{tabular}{|c|c|c|c|c|c|}
\hline Cluster & Variável & $\begin{array}{c}\text { Míni- } \\
\text { mo }\end{array}$ & $\begin{array}{l}\text { Má- } \\
\text { ximo }\end{array}$ & $\begin{array}{l}\text { Mé- } \\
\text { dia }\end{array}$ & $\begin{array}{l}\text { Desvio } \\
\text { padrão }\end{array}$ \\
\hline \multirow{17}{*}{$\begin{array}{l}1 \\
\text { Na=47 } \\
\text { Melhor } \\
\text { Avaliação }\end{array}$} & Acessibilidade & 1 & 5 & 3,50 & 0,93 \\
\hline & Segurança & 1 & 5 & 2,83 & 1,26 \\
\hline & Privacidade em relação à vizinhança & 1 & 5 & 3,42 & 0,97 \\
\hline & Aparência & 2 & 5 & 4,10 & 0,67 \\
\hline & Localização & 1 & 5 & 3,70 & 0,80 \\
\hline & Qualidade do abastecimento de água & 2 & 5 & 4,28 & 0,58 \\
\hline & Qualidade da rede de esgoto & 1 & 5 & 3,74 & 1,01 \\
\hline & Qualidade da coleta de lixo & 2 & 5 & 4,04 & 0,75 \\
\hline & Qualidade da iluminação pública & 1 & 5 & 3,74 & 0,85 \\
\hline & Qualidade do escoamento de água da chuva & 1 & 5 & 3,82 & 0,98 \\
\hline & Qualidade das ruas & 3 & 5 & 4,11 & 0,56 \\
\hline & Qualidade das calçadas & 3 & 5 & 4,25 & 0,53 \\
\hline & Qualidade da rede e sinal de telefonia & 1 & 4 & 1,65 & 0,81 \\
\hline & Qualidade das áreas de lazer & 1 & 5 & 2,98 & 1,09 \\
\hline & Qualidade das áreas de convivência & 1 & 4 & 2,31 & 1,01 \\
\hline & Acesso ao transporte público & 1 & 5 & 3,16 & 1,03 \\
\hline & Qualidade do transporte público & 1 & 5 & 3,46 & 0,80 \\
\hline
\end{tabular}




\begin{tabular}{|c|c|c|c|c|c|}
\hline Cluster & Variável & $\begin{array}{l}\text { Míni- } \\
\text { mo }\end{array}$ & $\begin{array}{l}\text { Má- } \\
\text { ximo }\end{array}$ & $\begin{array}{l}\text { Mé- } \\
\text { dia }\end{array}$ & $\begin{array}{l}\text { Desvio } \\
\text { padrão }\end{array}$ \\
\hline \multirow{17}{*}{$\begin{array}{l}2 \\
\mathrm{Na}=53 \\
\text { Pior Ava- } \\
\text { liação }\end{array}$} & Acessibilidade & 1 & 5 & 2,90 & 1,14 \\
\hline & Segurança & 1 & 5 & 1,81 & 1,05 \\
\hline & Privacidade em relação à vizinhança & 1 & 5 & 2,72 & 1,40 \\
\hline & Aparência & 2 & 5 & 3,67 & 0,92 \\
\hline & Localização & 1 & 5 & 2,41 & 1,17 \\
\hline & Qualidade do abastecimento de água & 4 & 5 & 4,41 & 0,50 \\
\hline & Qualidade da rede de esgoto & 1 & 5 & 3,79 & 1,18 \\
\hline & Qualidade da coleta de lixo & 1 & 5 & 3,92 & 0,98 \\
\hline & Qualidade da iluminação pública & 1 & 5 & 3,13 & 0,97 \\
\hline & Qualidade do escoamento de água da chuva & 1 & 5 & 3,51 & 0,99 \\
\hline & Qualidade das ruas & 1 & 5 & 3,94 & 0,87 \\
\hline & Qualidade das calçadas & 2 & 5 & 4,03 & 0,76 \\
\hline & Qualidade da rede e sinal de telefonia & 1 & 2 & 1,08 & 0,28 \\
\hline & Qualidade das áreas de lazer & 1 & 5 & 1,76 & 1,03 \\
\hline & Qualidade das áreas de convivência & 1 & 4 & 1,59 & 0,78 \\
\hline & Acesso ao transporte público & 1 & 4 & 2,10 & 1,05 \\
\hline & Qualidade do transporte Público & 1 & 4 & 2,19 & 1,08 \\
\hline
\end{tabular}

Fonte: os autores.

Nota: ${ }^{a}$ Número de famílias em cada Cluster.

A interpretação da Análise de Variância, disposta na Tabela 4, permitiu identificar quais variáveis mais contribuem para a separação dos Clusters na dimensão empreendimento. 
Tabela 4 - Anova da dimensão Empreendimento

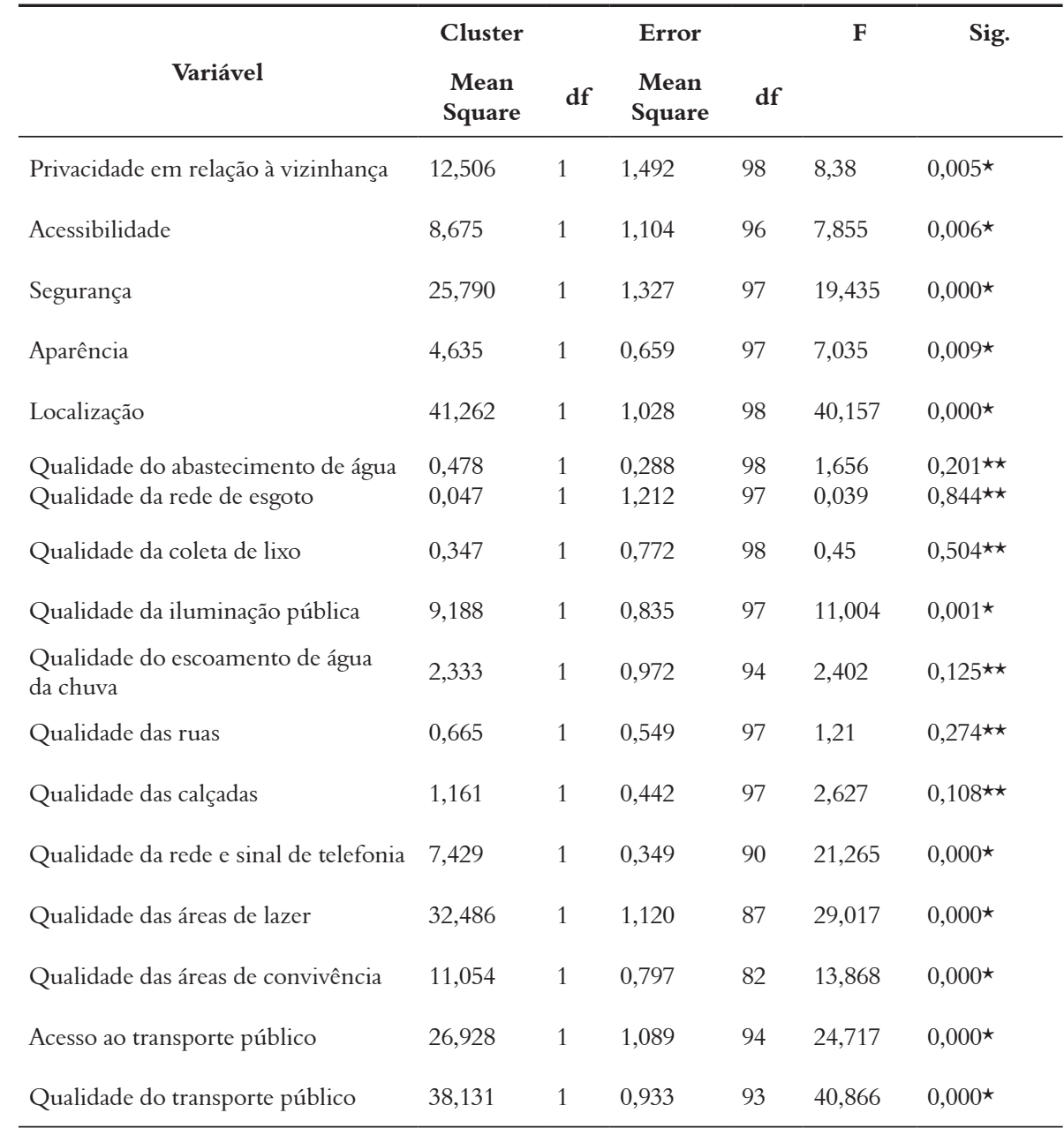

Fonte: os autores.

Nota: ${ }^{\star}$ significativo a $5 \%,{ }^{\star}$ não significativo.

Observa-se, na Tabela 4, que nove das 17 variáveis utilizadas no constructo empreendimento foram significativas para a formação dos Clusters, ao nível de 5\% de significância.

Com base na magnitude dos valores de $\mathrm{F}$, conclui-se que as variáveis qualidade do transporte público $(\mathrm{F}=40,866)$; localização do empreendimento $(\mathrm{F}=40,157)$; qualidade das áreas de lazer $(\mathrm{F}=29,017)$; acesso ao transporte público $(\mathrm{F}=24,717)$; qualidade da rede e sinal de telefonia $(\mathrm{F}=21,265)$ e segurança no empreendimento $(\mathrm{F}=19,435)$ foram 
as que mais contribuíram para discriminar as famílias que melhor e pior avaliaram as características do empreendimento.

Pela baixa magnitude da variabilidade interna das variáveis (coluna Error Mean Square), atribui-se a maior significância das variáveis supracitadas à sua variabilidade externa, isto é, entre os Clusters (coluna Cluster Mean Square).

A importância da variável localização do empreendimento, relacionada com a integração do empreendimento à cidade, e das variáveis qualidade do transporte público e acesso ao transporte público, vinculadas ao serviço público que viabiliza essa integração, condizem com os relatos que apontavam a distância do empreendimento às principais áreas da cidade e a ineficiência do transporte público em "reduzir o efeito" dessa distância. Foi enfatizada, pelas famílias entrevistadas, a necessidade de mais horários de ônibus no decorrer do dia.

A principal via de acesso ao empreendimento é composta por um morro íngreme. Dessa forma, o serviço é prestado utilizando as vias das imediações, que são estradas sem cobertura asfáltica. Segundo a representante do bairro, “[...] quando há período das chuvas ficamos sem o serviço de ônibus.” (informação verbal).

Destaca-se, ainda, nos valores de F, a variável qualidade da rede e sinal de telefonia (tanto fixa quanto móvel). Embora sua variabilidade externa esteja entre as menores, apresenta um dos maiores valores de $\mathrm{F}$, em razão de a variabilidade interna ser baixa $(0,349)$. Tal resultado pode ser confirmado na percepção dos beneficiários, pois $87 \%$ dos entrevistados (de ambos os Clusters) avaliaram-na como péssima ou ruim.

Durante a coleta dos dados, os beneficiários foram uníssonos em se queixar da falta de sinal de telefonia celular e da ausência de telefone público (orelhão) no bairro. A referida situação foi reportada pela representante do bairro à empresa responsável pelo serviço três meses após a inauguração do empreendimento. Relata, também, que após a primeira solicitação, receberam a visita do engenheiro responsável, que verificou e autorizou a implantação do serviço. Contudo, até o momento da pesquisa, a situação não havia sido resolvida, e "[...] a falta de acesso a esse serviço inviabiliza a comunicação na comunidade causando alguns transtornos para os moradores que necessitam [dele]". (informação verbal).

A segurança no empreendimento, outro item de destaque na estatística F, tem análise complementar por meio dos relatos de situações de roubos, furtos, violência, invasões, e também casos de venda e uso de entorpecentes dentro do conjunto habitacional. De acordo com um relatório da situação irregular dos imóveis expedidos pela representante do bairro à Caixa Econômica Federal (CEF), existem seis casas nessa situação, como: "A Sra. X não ocupou o imóvel no prazo de 30 dias 
determinado pela Caixa [...] após dois meses a residência foi depredada por vândalos e a Sra. Y, não participante do PMCMV ocupou o imóvel"; e "A Sra. W ocupou o imóvel logo após a entrega da chaves”, seis meses depois “[...] ocorreu uma situação de violência [...] prezando por sua segurança e de sua família, desocupou o imóvel [...] (informação verbal).

A qualidade das áreas de lazer diz respeito aos espaços destinados à recreação e ao entretenimento. Foi observada a existência de apenas uma área de lazer, destinada a crianças - playground. Entretanto, moradores relataram que alguns brinquedos se encontravam deteriorados e sem conservação, representando até perigo para crianças menores. Relataram, também, que em determinado horário do dia (mais especificamente ao entardecer) a área é utilizada por indivíduos que consomem entorpecentes.

É importante observar que, mesmo com pequena diferença, existem mais famílias insatisfeitas (53) do que famílias satisfeitas (47) quando se avalia a dimensão empreendimento. Novamente, revela-se a insatisfação das famílias beneficiárias pelo Programa em Viçosa, MG.

\subsubsection{Entorno}

$\mathrm{Na}$ Tabela 5 apresenta-se a caracterização dos Clusters formados a partir da dimensão entorno. Constatou-se que a média geral do primeiro agrupamento foi de 3,18 e a do segundo, de 2,27 pontos. 
Tabela 5 - Caracterização dos Clusters da Dimensão Entorno

\begin{tabular}{|c|c|c|c|c|c|}
\hline Cluster & Variável & $\begin{array}{l}\text { Míni- } \\
\text { mo }\end{array}$ & $\begin{array}{l}\text { Máxi- } \\
\text { mo }\end{array}$ & Média & $\begin{array}{l}\text { Desvio } \\
\text { padrão }\end{array}$ \\
\hline \multirow{19}{*}{$\begin{array}{l}1 \\
\mathrm{Na}=55 \\
\text { Melhor } \\
\text { Avaliação }\end{array}$} & Qualidade da iluminação pública & 1 & 5 & 2,93 & 1,16 \\
\hline & Qualidade das ruas & 1 & 5 & 3,00 & 1,06 \\
\hline & \multirow{3}{*}{$\begin{array}{l}\text { Qualidade das calçadas } \\
\text { Qualidade do escoamento de } \\
\text { água da chuva } \\
\text { Qualidade da praça }\end{array}$} & 1 & 5 & 3,00 & 1,06 \\
\hline & & 1 & 5 & 3,31 & 0,81 \\
\hline & & 1 & 5 & 3,35 & 0,92 \\
\hline & Acesso ao trabalho & 1 & 5 & 2,87 & 0,99 \\
\hline & Acesso ao comércio/serviços & 1 & 4 & 2,72 & 1,08 \\
\hline & Acesso à educação & 1 & 5 & 3,66 & 0,74 \\
\hline & Acesso ao lazer & 1 & 5 & 3,17 & 0,97 \\
\hline & Acesso à saúde & 1 & 4 & 1,80 & 0,96 \\
\hline & Acesso ao esporte & 1 & 4 & 3,00 & 1,03 \\
\hline & Acesso a atividades culturais & 1 & 4 & 2,81 & 1,00 \\
\hline & Acesso à assistência social & 1 & 5 & 3,17 & 0,95 \\
\hline & Qualidade do comércio/serviços & 1 & 5 & 3,81 & 0,64 \\
\hline & Qualidade da educação & 3 & 5 & 4,12 & 0,50 \\
\hline & Qualidade do lazer & 1 & 5 & 3,51 & 0,88 \\
\hline & Qualidade da saúde & 1 & 5 & 3,28 & 1,28 \\
\hline & Qualidade do esporte & 1 & 5 & 3,26 & 1,18 \\
\hline & $\begin{array}{l}\text { Qualidade das atividades cul- } \\
\text { turais }\end{array}$ & 1 & 5 & 3,23 & 1,11 \\
\hline & Qualidade da assistência social & 1 & 5 & 3,66 & 0,85 \\
\hline & Qualidade da Iluminação pública & 1 & 4 & 2,73 & 1,09 \\
\hline & Qualidade das ruas & 1 & 5 & 2,09 & 0,98 \\
\hline & Qualidade das calçadas & 1 & 5 & 1,84 & 0,89 \\
\hline & $\begin{array}{l}\text { Qualidade do escoamento de } \\
\text { água da chuva }\end{array}$ & 1 & 4 & 2,57 & 0,98 \\
\hline & Qualidade da praça & 1 & 4 & 2,42 & 0,89 \\
\hline & Acesso ao trabalho & 1 & 4 & 1,76 & 0,80 \\
\hline & Acesso ao comércio/serviços & 1 & 4 & 1,78 & 0,88 \\
\hline & Acesso a educação & 1 & 5 & 2,42 & 1,15 \\
\hline 2 & Acesso ao lazer & 1 & 4 & 1,87 & 0,79 \\
\hline $\mathrm{Na}=45$ & Acesso a saúde & 1 & 3 & 1,20 & 0,46 \\
\hline Pior Ava- & Acesso ao esporte & 1 & 5 & 1,83 & 1,00 \\
\hline liação & Acesso a atividades culturais & 1 & 4 & 1,76 & 0,83 \\
\hline & Acesso a assistência social & 1 & 5 & 3,03 & 1,13 \\
\hline & Qualidade do comércio/serviços & 1 & 4 & 2,93 & 1,17 \\
\hline & Qualidade da educação & 1 & 5 & 3,37 & 1,24 \\
\hline & Qualidade do lazer & 1 & 4 & 1,90 & 0,89 \\
\hline & Qualidade da saúde & 1 & 5 & 2,55 & 1,25 \\
\hline & Qualidade do esporte & 1 & 4 & 2,00 & 0,96 \\
\hline & $\begin{array}{l}\text { Qualidade das atıvidades cul- } \\
\text { turais }\end{array}$ & 1 & 4 & 1,93 & 0,89 \\
\hline & Qualidade da assistência social & 1 & 5 & 3,44 & 1,05 \\
\hline
\end{tabular}


Observa-se que as médias do Cluster 1 são superiores às médias do Cluster 2, motivo pelo qual foram definidos como "Melhor Avaliação" e "Pior Avaliação", respectivamente. Na Tabela 6, apresenta-se a Análise de Variância para as variáveis do constructo entorno.

Tabela 6 - Anova da dimensão Entorno

\begin{tabular}{|c|c|c|c|c|c|c|}
\hline \multirow[b]{2}{*}{ Variável } & \multicolumn{2}{|c|}{ Cluster } & \multirow{2}{*}{$\begin{array}{c}\text { Error } \\
\text { Mean Squa- } \\
\text { re }\end{array}$} & \multirow[b]{2}{*}{ df } & \multirow[b]{2}{*}{$\mathbf{F}$} & \multirow[t]{2}{*}{ Sig. } \\
\hline & $\begin{array}{c}\text { Mean } \\
\text { Square }\end{array}$ & df & & & & \\
\hline $\begin{array}{l}\text { Qualidade da iluminação } \\
\text { pública }\end{array}$ & 0,910 & 1 & 1,284 & 97 & 0,709 & $0,402^{\star \star}$ \\
\hline Qualidade das ruas & 20,037 & 1 & 1,059 & 96 & 18,926 & $0,000^{\star}$ \\
\hline Qualidade das calçadas & 32,573 & 1 & 0,978 & 96 & 33,306 & $0,000^{\star}$ \\
\hline $\begin{array}{l}\text { Qualidade do escoamento de } \\
\text { água da chuva }\end{array}$ & 11,437 & 1 & 0,780 & 84 & 14,655 & $0,000^{\star}$ \\
\hline Qualidade da praça & 18,347 & 1 & 0,828 & 85 & 22,163 & $0,000^{\star}$ \\
\hline Acesso ao trabalho & 25,765 & 1 & 0,830 & 82 & 31,049 & $0,000^{\star}$ \\
\hline Acesso ao comércio/serviços & 22,313 & 1 & 0,987 & 98 & 22,616 & $0,000^{\star}$ \\
\hline Acesso à educação & 31,253 & 1 & 0,914 & 80 & 34,180 & $0,000^{\star}$ \\
\hline Acesso ao lazer & 33,993 & 1 & 0,787 & 79 & 43,188 & $0,000^{\star}$ \\
\hline Acesso a saúde & 8,910 & 1 & 0,592 & 98 & 15,055 & $0,000^{\star}$ \\
\hline Acesso ao esporte & 20,595 & 1 & 1,037 & 58 & 19,863 & $0,000^{\star}$ \\
\hline Acesso a atividades culturais & 16,599 & 1 & 0,830 & 58 & 20,001 & $0,000^{\star}$ \\
\hline Acesso à assistência social & 0,361 & 1 & 1,066 & 72 & 0,338 & $0,563 \star \star$ \\
\hline $\begin{array}{l}\text { Qualidade do comércio/ } \\
\text { serviços }\end{array}$ & 19,072 & 1 & 0,855 & 97 & 22,303 & $0,000^{\star}$ \\
\hline Qualidade da educação & 10,671 & 1 & 0,834 & 75 & 12,789 & $0,001^{\star}$ \\
\hline Qualidade do lazer & 50,392 & 1 & 0,791 & 75 & 63,709 & $0,000^{\star}$ \\
\hline Qualidade da saúde & 12,243 & 1 & 1,605 & 90 & 7,627 & $0,007 \star$ \\
\hline Qualidade do esporte & 23,715 & 1 & 1,171 & 58 & 20,246 & $0,000^{\star}$ \\
\hline $\begin{array}{l}\text { Qualidade das atividades } \\
\text { culturais }\end{array}$ & 23,724 & 1 & 0,991 & 55 & 23,948 & $0,000^{\star}$ \\
\hline $\begin{array}{l}\text { Qualidade da assistêncıa } \\
\text { social }\end{array}$ & 0,879 & 1 & 0,908 & 75 & 0,968 & 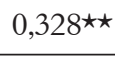 \\
\hline
\end{tabular}

Fonte: os autores.

Nota: ${ }^{\star}$ significativo a $5 \%, \star \star$ não significativo.

À exceção de três variáveis (iluminação pública, acesso à assistência social e qualidade da assistência social), as demais utilizadas no constructo entorno foram significativas para a formação dos Clusters, ao nível de significância de $5 \%$, conforme apresentado na Tabela 6 . 
Pode-se perceber que as variáveis com maior variabilidade externa, isto é, entre os Clusters, foram: qualidade das calçadas do entorno, acesso ao trabalho, acesso à educaşão, acesso ao lazer e qualidade do lazer, o que pode ser visualizado na coluna Cluster Mean Square. Já as variabilidades internas dessas variáveis estão entre as menores, como pode ser verificado na coluna Error Mean Square.

A combinação maior Cluster Mean Square e menor Error Mean Square gera maior valor da estatística $\mathrm{F}$, como se pode observar nas variáveis que mais contribuíram para a distinção dos Clusters, a saber: qualidade do lazer $(\mathrm{F}=63,709)$; acesso ao lazer $(\mathrm{F}=43,188)$; acesso à educação $(\mathrm{F}=34,180)$; qualidade das calçadas do entorno $(\mathrm{F}=33,306)$ e acesso ao trabalho $(\mathrm{F}=31,049)$.

A qualidade do lazer e seu acesso são itens que merecem a atenção dos gestores e dizem respeito à oferta e ao uso de atividades de entretenimento fora do conjunto habitacional. Segundo relatos dos beneficiários, faltam opções de lazer e as que existem e são de sua preferência encontram-se distantes do empreendimento.

As vias destinadas exclusivamente à circulação de pedestres em áreas vizinhas ao empreendimento foram avaliadas pela qualidade das calçadas do entorno. Nota-se que esse item foi relevante na percepção das famílias, pelo fato de elas trafegarem a pé nas regiões próximas ao empreendimento, em razão, inclusive, da falta de horários de transporte público, anteriormente mencionada. Em observação in loco, durante a pesquisa de campo, esse item realmente revelou-se precário e, em algumas áreas, inexistente.

Outro ponto a ser analisado é o acesso ao trabalho, o deslocamento que o indivíduo tem que realizar diariamente para exercer atividades produtivas remuneradas (emprego formal ou informal). Como supramencionado, foi relatado que o empreendimento está distante dos locais de trabalho e que os horários de transporte público não atendem às necessidades da maioria dos moradores.

E, por fim, comenta-se sobre o acesso à educação, que preconiza a oferta dos serviços de educação, bem como o deslocamento até as escolas. O relato das famílias que continham em seu núcleo indivíduos estudantes foi que, embora houvesse transporte escolar, em dias chuvosos este não era disponibilizado por impossibilidade de trafegar em estradas de chão. Somado a isso, não há disponibilidade de escolas próximas ao entorno para todos os níveis escolares.

Embora se tenha destacado as variáveis anteriores, observa-se que as demais apresentam estatística F com escores próximos e elevados, permitindo inferir, de forma geral, que as diversas variáveis do entorno foram relevantes para a formação dos Clusters. E, portanto, muitas delas são importantes para a percepção 
dos beneficiários, o que leva à afirmar que devem ser contempladas pelos gestores públicos, para que as famílias alocadas no conjunto habitacional estudado tenham condições de realizar suas atividades básicas.

\section{CONSIDERAÇÕES FINAIS}

Interessante notar que, embora se tenha dividido o conjunto de variáveis em constructos, pode-se detectar uma transversalidade importante em determinados aspectos. Por exemplo, as variáveis significativas na formação dos Clusters: localização do empreendimento, qualidade do transporte público e acesso ao transporte público, qualidade das calçadas do entorno, acesso ao trabalho, acesso à educação e acesso ao lazer estão diretamente relacionadas com a escolha do terreno, ponto crucial para projetos de habitação de interesse social. A escolha deve estar balizada na existência ou viabilidade de infraestrutura, equipamentos comunitários e transporte público, bem como a inserção na malha urbana. Ao trazer a percepção dos beneficiários, é possível verificar sua proximidade com essas necessidades técnicas e projetuais.

Constatou-se que o lazer também foi um aspecto negligenciado pelos gestores do Programa, tanto dentro do empreendimento quanto em seu entorno, como pode ser observado nas variáveis qualidade das áreas de lazer no empreendimento, qualidade do lazer no entorno e acesso ao lazer.

Outro aspecto relevante foi a segurança, ou melhor, a falta dela, e o consensual sentimento de insegurança decorrente dos episódios de violência, vandalismo, invasões e do uso e comércio de entorpecentes. Isso foi demonstrado pela significância das variáveis segurança da unidade habitacional, qualidade das portas e janelas e segurança do empreendimento. A variável qualidade da rede e sinal de telefonia é um agravante, pois a ausência de telefone público (orelhão) e a falta de sinal de telefone móvel (celular) impedem possíveis comunicações com a polícia.

Com base nas análises comparativas entre as três dimensões, pode-se perceber a segregação do espaço urbano quando se trata da provisão habitacional para a população de baixa renda (interesse social). Esses indivíduos são alocados em locais distantes (regiões periféricas) das principais áreas urbanas. Considera-se, nesse sentido, que um programa que tem em seu escopo a diretriz de construir moradias que sejam capazes de promover a sustentabilidade social, ambiental e econômica dos conjuntos, deve atentar-se a estudos avaliativos dessa natureza. O caso de Viçosa, 
MG indicou, com base na percepção daqueles que de fato usufruem do benefício, diversos pontos críticos que devem ser repensados.

Embora não haja evidências empíricas que permitam extrapolar os achados do artigo, convém destacar que o caso estudado demonstrou a desarticulação entre as políticas urbanas. O que se constatou foi a provisão habitacional desintegrada de uma série de ações públicas destinadas ao ordenamento urbano, como mobilidade urbana, cultura e lazer, por exemplo.

Com isso, a avaliação de programas de habitação de interesse social, especificamente por meio de pesquisas com ênfase na percepção dos beneficiários, é de notória importância para subsidiar os profissionais e gestores públicos com instrumentos para o aperfeiçoamento das políticas, com vistas à melhor alocação dos recursos e ao aumento do bem-estar da população.

Por fim, destaca-se que a Matriz de Estrutura Lógica demonstrou ser capaz de orientar e estruturar a avaliação de resultados do PMCMV sob a perspectiva do beneficiário, explicitando de forma clara e simples os objetivos do Programa, suas variáveis-chave para análise e seus indicadores. Além disso, a Análise de Cluster mostrou-se adequada para avaliar os resultados do Programa Minha Casa Minha Vida em Viçosa, MG, com base na percepção dos beneficiários. Os resultados indicam que essa metodologia multivariada é promissora para estudos dessa natureza, pois permitiu, inclusive, eficaz identificação das variáveis que mais contribuíram para a separação dos grupos que melhor e pior avaliaram a unidade habitacional, o empreendimento e seu entorno, refletindo fidedignamente nas manifestações dos entrevistados.

\section{REFERÊNCIAS}

BAMBERGER, M.; RUGH, J.; MABRY, L. Real World Evaluation. Working Under Budget, Time, Data and Political Constraints. SAGE, 2006.

BANCO INTERAMERICANO DE DESARROLLO. Evaluación: una herramienta de gestión para mejorarel desempeno de losproyectos. Marzo 1997.

BANCO MUNDIAL. Seguimiento evaluación: instrumentos, métodos y enfoques. Washington: 2004.

BONATTO, F. S.; MIRON, L. I. G.; FORMOSO, C. T. Avaliação de empreendimentos habitacionais de interesse social com base na hierarquia de valor percebido pelo usuário. Ambiente Construído, v. 11, n. 1, 2011. 
BRASIL. Ministério das Cidades. Dispõe sobre as diretrizes gerais para aquisição e alienação de imóveis por meio da transferência de recursos ao Fundo de Arrendamento Residencial - FAR, no âmbito do Programa Nacional de Habitação Urbana - PNHU, integrante do Programa Minha Casa, Minha Vida - PMCMV. Portaria n. 465, de 03 de outubro de 2011. Diário Oficial [da] República Federativa do Brasil, Brasília, DF, Seção 1, p. 31-36, 2011.

BRASIL. Ministério das Cidades. Matriz de indicadores para avaliação do pós-ocupação dos projetos piloto de investimento Intervenção em favelas. Brasília, DF: Secretaria Nacional de Habitação: Programa Habitar Brasil: BID: Ministério das Cidades, 2009.

CALDAS, E. de L.; KAYANO, J. Indicadores para o Diálogo. São Paulo: Instituto Pólis: PGPC-EAESP-FGV: CEDEC, 2001.

COHEN, E.; FRANCO, R. Avaliação de projetos sociais. Petrópolis: Vozes, 2008.

COSTA, F. L.; CASTANHAR, J. C. Avaliação de programas públicos: desafios conceituais e metodológicos. Revista de Administração Pública, v. 37, n. 5, p. 969-992, 2003.

FÁVERO, L. P. Análise de dados: modelagem multivariada para tomada de decisões. Rio de Janeiro: Elsevier, 2009.

FUNDAÇÃO JOÃO PINHEIRO. Centro de Estatísticas e Informações. Déficit habitacional no Brasil 2011-2012: resultados preliminares. Belo Horizonte: Fundação João Pinheiro: Centro de Estatísticas e Informações, 2014.

HAIR JUNIOR, J. F. et al. Multivariate data analysis. 5th. ed. Upper Saddle River, NJ: Prentice Hall, 1998.

LIMA, L. P.; FORMOSO, C. T.; ESCHEVESTE, M. E. S. Proposta de um protocolo para o processamento de requisitos do cliente em empreendimentos habitacionais de interesse social. Ambiente Construído, v. 11, n. 2, p. 21-37, 2011.

MARDIA, K. V.; KENT, J. T.; BIBBY, J. M. Multivariate Analysis. San Diego, CA: Academic Press Inc., 1979. 518 p.

MAROCO, J. Análise Estatística com Utilização do SPSS. 3. ed. Lisboa: Sílabo, 2007. 
MARTINS, G. A. Sobre Confiabilidade e Validade. Revista Brasileira de Gestão de Negócios, n. 7, 2007.

MORAES, O. B.; ABIKO, A. K. Utilização da análise fatorial para a identificação de estruturas de interdependência de variáveis em estudos de avaliação pós-ocupação. In: ENCONTRO NACIONAL DE TECNOLOGIA NO AMBIENTE CONSTRUÍDO, 11., 2006, Florianópolis. Anais... Florianópolis, 2006.

MORRA-IMAS, L. G.; RIST, R. C. The road to results: designing and conducting effective development evaluations. The World Bank, 2009.

ORNSTEIN, S.; ROMÉRO, M. Avaliação Pós-Ocupação do ambiente construído. São Paulo: Studio Nobel: Ed. Universidade de São Paulo, 1992.

ORTEGON, E.; PACHECO, J. F.; PRIETO, A. Metodologíadel marco lógico para laplanificación, elseguimiento y laevaluación de proyectos y programas. CEPAL, 2005.

PFEIFFER, P. O quadro lógico: um método para planejar e gerenciar mudanças. Revista do Serviço Público, Brasília, DF: ENAP, v. 51, n. 1, p. 81-123, 2000.

REIS, F. N. S. C. Programa Minha Casa, Minha Vida: Estrutura Lógica, Focalização e Percepção dos Beneficiários. 2013. 159 p. Dissertação (Mestrado em Administração)-Universidade Federal de Viçosa, Viçosa, 2013.

ROSSI, P. H.; LIPSEY, M. W.; FREEMAN, H. E. Evaluation: a systematic approach. California: SAGE, 2004.

SANTOS, A. M. C. dos. Sociabilidade e ajuda mútua na periferia urbana de Viçosa, Minas Gerais. 1991. 351 p. Dissertação (Mestrado em Extensão Rural)Universidade Federal de Viçosa, Viçosa, 1991.

SOUZA, S. U. N. Direito à moradia e de habitação: Análise comparativa e suas implicações teóricas e práticas com os direitos da personalidade. 2. ed. São Paulo: [S.1.], 2008.

TRIVIÑOS, A. N. S. Introdução à pesquisa em ciências sociais: a pesquisa qualitativa em educação. São Paulo: Atlas, 1987.

UNITED NATIONS DEVELOPMENT PROGRAMME. Handbook on Monitoring and Evaluation for Results, Evaluation Office. New York, 2002. 
VILlAROSA, F.; ABIKO, A. Ministério das Cidades. Secretaria Nacional de Habitação. Monitoramento e avaliação de programas de ação integrada em assentamentos precários. In: Curso a Distância, Módulo 3, Disciplina 11, Ações integradas de urbanização de assentamentos precários, 2015. Disponível em: <// alexabiko.ppc.usp.br/Apostila_11.pd >. Acesso em: 20 mar. 2015.

VOS, R. Hacia un sistema de indicadores sociales. Washington: BID/Indes, 1996.

W.K. KELLOGG FOUNDATION. Logic Model Development Guide: Using Logic Models to Bring Together Planning, Evaluation, and Action. W.K. Kellogg Fundation, 2004.

WOLLMANN, H. Policy evaluation and evaluation research. In: FISCHER, F.; MILLER, G. J.; SIDNEY, M. S. Handbook of public policy analysis: Theory, politics, and methods. New York: CRC Press, 2007.

WOODRUFF, R. B.; GARDIAL, S. Know Your Customer: new approaches to understanding customer value and satisfaction. Blackwell Publishing, 1996.

WORLD BANK. Designing Project Monitoring and Evaluation.

Washington, DC: World Bank: Operations Evaluation Department, 1996.

\section{COMO CITAR ESTE ARTIGO:}

REIS, Francimar Natália Silva Cruz; SILVEIRA, Suely de Fátima Ramos;

F MOREIRA, Vinicius de Souza. Resultados do Programa Minha Casa Minha

Vida sob a Percepção dos Beneficiários. RACE, Revista de Administração, Contabilidade e Economia, Joaçaba: Ed. Unoesc, v. 14, n. 3, p. 925-956, set./ dez. 2015. Disponível em: < http://editora.unoesc.edu.br/index.php/race> Acesso em: dia/mês/ano.

$\overleftrightarrow{\&}$ Reis, F. N. S. C., Silveira, S. de F. R., \& Moreira, V. de S. (2015). Resultados do Programa Minha Casa Minha Vida sob a Percepção dos Beneficiários. RACE, Revista de Administração, Contabilidade e Economia, 14(3), 925-956. Recuperado em dia/mês/ano, de http://editora.unoesc.edu.br/index.php/race 
